\title{
EDITORIAL
}

\section{Tune in while you tune out}

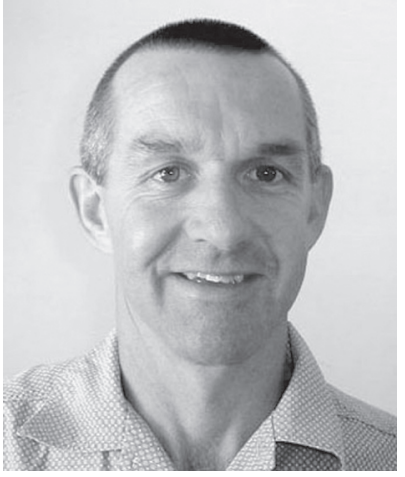

While I was training in the gym last week I counted 23 out of the 49 people in the gym at that time with earphones and music devices. The people using these devices ranged from young, bodyconscious teenagers, to older folk, old enough to be their grandparents. Whatever they were listening to remained a mystery but a safe bet would be anything from classical to golden oldies to hip-hop. There is no doubt that this new exercise-associated behaviour is here to stay. There were a few false starts in the 1980s and 1990s with appearance of the popular Sony walkmans, but they were too bulky and were not widely used during exercise. Furthermore, it was mostly the younger generation that used these music players in public.

The development of iPods in 2001 marked the beginning of the music and exercise 'fashion'. Fashion is probably an inappropriate term because iPods have stood the test of time and outlasted many other exercise-associated fads. Since the development of the first batch of iPods, 110 million have been sold worldwide and there are probably double the number of people using portable media players, certainly if the inexpensive, less sophisticated brands of MP3 players and cell phone/MP players are also considered in the estimate.

New behaviour leads to new questions and new questions lead to research. Some scientists have already studied the effects of music while exercising. A quick perusal of the literature shows that over 150 studies have been conducted in the last 2 years. The message these studies convey is generally positive, with many studies showing that there may certainly be advantages in listening to music while exercising, particularly where there is a high risk of poor compliance. Studies have also shown that older people with dementia have improved cognitive function if they listen to music while exercising. Furthermore, many of the problems associated with Alzheimer's disease can sometimes be delayed, retarded, or even reversed with proper exercise. ${ }^{1}$ A body of research shows that music with activity brings about the greatest degree of responsiveness in these patients. It might not only be music that people listen to while exercising. As more electronic books become available it is conceivable that many people will choose to listen to their favourite novel while they pedal away the calories. Indeed, there is probably a place in the market for the production of study notes which can be listened to while exercising. If the research on older patients is considered, a case can be made that listening to study notes while exercising might prove to be an efficient way to retain information, even a study enhancer?

Not all the studies about music during exercise are supportive - Fligor and Cox studied the sound levels generated by a range of headphones and found that certain types of earphones are safer than others. ${ }^{2}$ The study showed that the average person listens to music at the same noise level generated by a petrol lawnmower. This behaviour can have long-term effects that impair hearing. They recommended that for ear health one should invest in earphones that block out background noise, set the volume to a comfortable level in a quiet environment, and limit the duration to about 60 minutes.

On another note, a fascinating article has just been published in Nature, showing that $20 \%$ of scientists polled admitted to using performance-enhancing prescription drugs. ${ }^{3}$ The 1400 respondents were from 60 countries and were asked about their use of 3 drugs: methylphenidate (Ritalin), a stimulant normally used to treat attention-deficit hyperactivity disorder, modafinil (Provigil), prescribed to treat sleep disorders, and beta blockers. Ritalin was the most well-used drug ( $62 \%$ of users) followed by modafinil $(44 \%)$ and beta blockers $(15 \%)$. Nearly $70 \%$ of the respondents said they would be willing to risk mild side-effects to be able to "boost your brain power' by taking cognitive-enhancing drugs. Given these results, if a random sample of academics underwent the same drug test that athletes have to undergo, about $20 \%$ would be tested positive - this prevalence ranks high among the sports renowned for competitors who use drugs to boost performance (e.g. cycling, body building). As a community, scientists need to drop the 'holier than thou attitude' when an athlete has a positive drug test! Could this mean that scientists have to have drug tests before submitting a paper for publication, or before a public presentation? Makes one think!

\section{Mike Lambert \\ Editor-in-Chief}

1. Cevasco AM, Grant RE. Comparison of different methods for eliciting exercise-to-music for clients with Alzheimer's disease. J Music Ther 2003; 40(1): 41-56.

2. Fligor BJ, Cox LC. Output levels of commercially available portable compact disc players and the potential risk to hearing. Ear Hear 2004; 25(6): 513-27.

3. Maher B. Poll results: look who's doping. Nature 2008; 452: 674-75. 